\title{
Recipe for less disaster
}

The first ever report of the recently formed UK Advisory Committee on Major Hazards (CMH), which recommends improved safety measures for potentially hazardous industrial installations, was published last week. Alastair Hay reports

THE new measures advocated in the CMH report* could provide a framework for the safer building and siting of industrial plants in Britain. The report considers the hazards of "explosion, the sudden release of toxic substances (and) cataclysmic fire", and industries that would come under closer scrutiny include those producing fertilisers, explosives, petrochemicals and nylon and other polymers. Nuclear installations are not considered in the report.

The report is the first of its kind to be produced as a result of a government commission in any country. The CMH was appointed by the Health and Safety Commission (HSC) following the disaster at the Nypro chemical plant at Tlixborough in June 1974, which killed 28 people, injured more than 100 , and

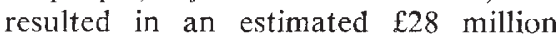
worth of damage to the immediately surrounding area. The Flixborough explosion was the most devastating in Britain since the end of World War II.

Prominent among the report's 38 recommendations is a call for a notification scheme that would allow the UK Health and Safety Commission (HSC) to identify particularly hazardous installations. In drawing up a list of notifiable installations the committee identifies 8 different types of plant, but ignores nuclear installations, in line with its original brief. An estimated 1,000-3,000 sites at present operating within the UK would fall within the proposed list, of which at least one in ten is operating to safety standards giving possible cause for concern, the report suggests. Moreover, while potentially notifiable plants are distributed throughout the UK, the report identifies specific areas of concentrated dcvelopment such as Teesside and Canvey Island where a chain reaction of explosions might pose an additional hazard. The proposed list of notifiable installations includes:

- those storing or processing toxic material where there could be an emission of toxic gases or vapours equivalent in effect to more than 10 tonnes of chlorine.

* Advisory Committee on Major Hazards. First report of the Health and Safety Executive. HMSO, £1.00.
- those storing or processing flammable materials where there could be a rapid emission of more than 15 tonnes of flammable gases or vapours.

- Those storing or processing more than 5 tonnes of materials which are intrinsically unstable or of very high exothermic reactivity. Examples are ethylene oxide, acetylenes, and organic peroxides.

Those with a large inventory of stored pressure energy, operating at 100 bars or more, using gas phase reactions.

- Those storing or processing more than 10,000 tonnes of flammable materials with a flashpoint of less than $22.8^{\circ} \mathrm{C}$

- Those storing or processing more than 135 tonnes of liquid oxygen.

- Those storing or processing more than 5,000 tonnes of ammonium nitrate.

- Those storing or processing materials which during a fire could cause an emission of toxic gases or vapours equivalent in effect to more than 10 tonnes of chlorine.

The list would apply to both existing and proposed installations, though the $\mathrm{CMH}$ has stressed that it is only provisional, and that a future list will almost certainly be wider ranging.

The report underlines the increasing importance of getting design and operating procedures right the first time. "Because of their present-day size, and throughput," the report says, "there are now many plants throughout the world where a critical first mistake can result in disaster". Moreover, the committee warns of the increased dangers to local communities: the report notes that while "the probability that an individual worker will be involved in a fatal accident has notably fallen, the chances [of] a plant failure . . . involving the public at large ... [have] become considerably greater".

Some of the specific proposals included in the report stem directly from recommendations made by the court of inquiry into the Flixborough disaster. For instance, the report advocates that industrial pipcwork, valves and pumps, at present often only tested before assembly, should also be tested following installation, when they form part of a total pressure system. It also recommends that any changes in the operating procedure at plants should be reported to the HSC for evaluation. Control rooms-that at Flixborough, built of brick, was completely destroyed in the explosion-should be single storey, reinforced concrete buildings, situated in a relatively safe area, while black box recorders similar to those used in air- craft, should be introduced to monitor plant operations, allowing the identification of fault sequences leading to accidents. Moreover, safety officers should have easy access to international data banks on industrial accidents and plant safety features, the report says.

The report advocates closer consultations between local authorities and the HSC when planning permission for new industrial plants is being considered. Neighbouring authorities likely to be affected by final decisions should also be included in the discussions. But the $\mathrm{CMH}$ has not yet considered the consequences of closing down potentially hazardous sites already in operation. At present, the compulsory closure of existing plant involves local authorities in the payment of considerable sums in compensation. The committee plans to discuss this problem with the Department of the Environment.

The Report does not advocate the enforced notification of 'near misses', which, it feels, could inhibit the flow of information. Mr James Tyc, director of the British Safety Council, welcoming the report, estimated that for every fatal accident in British Industry, there are three involving injury to workers, thirty resulting in damage to plant, and six hundred 'near misses'. Nonetheless, both industry and the HSC recognise that the lessons to be learned from a 'near miss' are as valid as those gained in the wake of a full-scale accident.

Professor Bryan Harvey, Chairman of the CMH, stressed the responsibility of management in introducing appropriate safety measures even before they became compulsory. Industry, he said, would in future have to give far more consideration to safety factors. Speaking for the chemical industry, Mr Donald Bennett, Chairman of the Chemical Industry Safety and Health Council, welcomed the report as "broadly consistent with the industry's own thinking on the form of control required". But he singled out areas needing further investigation, among them "the definition of the unit of notification", what parts of plants, processes or sites should be licenced, and the problem of selecting "truly independent experts" to act as arbitrators between industry and the HSC.

$\mathrm{Mr}$ Bennet's sentiments are not inconsistent with those of the $\mathrm{CMH}$ itself, outlined in the introduction to the report. The committee acknowledges the need for further discussion and research, and admits to the preliminary nature of much of the work completed so far; the report has been distributed to various interested organisations with requests for specific comments on the committee's proposals. 